\title{
FORMAÇÃO ‘IN LOCO’: DIVERSIDADE NA EDUCAÇÃO INFANTIL
}

\author{
Fernanda Pereira Da Silva Andrade ${ }^{9}$ \\ EMEI Zacarias Pereira da Silva/SME/PMU \\ fpsandrade2907@hotmail.com
}

Jozaene Maximiano Figueira Alves Faria ${ }^{10}$

EMEI Zacarias Pereira da Silva/SME/PMU

josyped@gmail.com

Resumo: Ampliar a reflexão sobre as possibilidades da formação continuada dos profissionais da educação infantil, levando em conta as exigências da legislação, das novas concepções da infância e da relação dialógica com a realidade, assegurando um espaço de interlocução para a análise e reflexão da própria prática e dos processos de ensino aprendizagem na perspectiva da Inclusão. O presente relato de experiência tem o objetivo de apresentar práticas de formação "in loco" de profissionais que atuam na EMEI Zacarias Pereira da Silva, que atende crianças de 0 a 3 anos. Oportunizando espaços de avaliação e discussão entre as demais atividades desenvolvidas nas instituições, para que a formação aconteça como um processo contínuo e integrado ao cotidiano, configurada não somente como necessidade, mas como direito e premissa para a oferta de uma Educação Infantil de qualidade.

\section{Um pouco de história e marcos legais}

Este relato de experiência se refere ao trabalho realizado na rede municipal de ensino de Uberlândia, especificamente na Escola Municipal de Educação Infantil Zacarias Pereira da Silva. Assim, na rede municipal de Ensino, sob diferentes nomenclaturas e gestões públicas, a formação continuada tem sido ofertada aos profissionais de Educação Infantil com formatos diversos: palestras, seminários, e,

9 Especialista em Tecnologia Digital aplicada à Educação; Especialista em Psicopedagogia e as Relações Psicoafetivas; Graduação em Pedagogia; Especialista em Educação: Supervisora Escolar na Rede Municipal de Ensino de Uberlândia.

10 Especialista em Psicopedagogia Escolar, professora da Educação Infantil na rede Municipal de Ensino de Uberlândia. 
mais recentemente, por meio da proposta intitulada, Formar Em Rede, em parceria com o Instituo Avisalá ${ }^{11}$, que vigorou pelo período de 2008 a 2012.

A formação, neste período, foi destinada aos Diretores, Vice-diretores e pedagogos no CEMEPE - Centro Municipal de Estudos e Projetos Educacionais Julieta Diniz e estes profissionais seriam os multiplicadores e formadores em suas respectivas unidades de ensino, seguindo um cronograma de trabalho e atividades previamente elaborados pela Assessoria Pedagógica e validado pelo setor mencionado acima.

A partir da Lei 11.444, que institui a Rede pelo Direito de Ensinar e Aprender, em 2013, as formações passaram a acontecer na sede do CEMEPE que prevê formações na sede do CEMEPE, nos polos e nas unidades escolares e em outros espaços formativos da cidade, e com a proposta de que as questões e temáticas de formação emergem nas intituladas "Rodas de Conversa" o ambiente escolar e em outros espaços de escuta. Desde então, a formação se dá em Rede, com a participação efetiva dos núcleos do CEMEPE, dos equipamentos sociais e da comunidade escolar.

Nas unidades escolares, cabe à gestão: diretor/a, vice-diretor/a, supervisor/a, orientador/a educacional e inspetor/a escolar, a responsabilidade de articular e planejar a formação nesse espaço ou no Polo onde a escola esteja situada, em parceria com os/as profissionais das unidades escolares circunvizinhas e equipe do CEMEPE. Pensando neste modelo de formação continuada, o presente trabalho surgiu com o objetivo de incentivar práticas de formação descentralizadas, a serem realizadas no interior das Escolas Municipais de Educação Infantil pertencentes à Rede Municipal de Ensino de Uberlândia, responsáveis pelo atendimento das crianças entre 0 a 5 anos, e popularmente conhecidas como EMEls.

11 O INSTITUTO AVISA LÁ é uma organização não-governamental (ONG), sem fins lucrativos, com finalidade pública. Desde 1986, vem contribuindo para qualificar a prática pedagógica das redes públicas de Educação Infantil. A partir de 2002 passou atuar também no Ensino Fundamental (séries iniciais) nas áreas de leitura, escrita e matemática. São exemplos dessa contribuição os diferentes programas de formação continuada que atingiram até o presente momento por volta de 200 municípios de diferentes estados brasileiros.

Vários membros da equipe técnica do Avisa Lá colaboraram intensamente com a elaboração dos Referenciais Curriculares para a Educação Infantil do MEC (1998), com os programas de formação e currículo da Secretaria Municipal de Educação da cidade de São Paulo. O Instituto Avisa Lá participa ativamente de programas do MEC tais como Indique para Educação Infantil e Ensino Fundamental em parceria com a ONG Ação Educativa, Diretrizes em ação em parceria com o UNICEF. 
A partir da Lei 11.967 , de 29 de Setembro de 2014 que dispõe sobre o Plano de Carreiras dos Servidores do Quadro da Educação da Rede Municipal de Ensino de Uberlândia em seu anexo IV Descrições das Atribuições das Especialidades nos Cargos: Pedagogo - Especialidades: Supervisor Escolar e Orientador Escolar fica normatizado que a estes profissionais cabe a função, entre outras:

Desenvolver a formação continuada in loco, promovendo e coordenando reuniões pedagógicas e grupos de estudo para reflexão e aprofundamento de temas relativos à prática pedagógica, visando à elaboração de propostas de intervenção para a qualidade do ensino; (Diário Oficial do Município de Uberlândia, MG, Ano XXVI, n. 4493, 29 set. 2014. p. 155-207.).

Em 24 de novembro de 2015 é publicada a lei 12.316, na qual consta o cargo de Educador Infantil com jornada de 25 (vinte e cinco) hora semanais, sendo que 01 (uma) hora deverá ser dedicada a estudos e formação continuada, a serem realizados na própria escola onde o servidor se encontra lotado.

A EMEI Zacarias Pereira da Silva, desde 2014, elabora e executa o seu Plano de Formação seguindo os marcos legais e as orientações prescritas pela Assessoria Pedagógica da Secretaria Municipal de Educação de Uberlândia e o presente relato de experiência corrobora a importância deste espaço de formação.

\section{Caminhos percorridos}

A formação in loco centrada no ambiente das escolas é uma prática defendida por Nóvoa (1995). Para o autor (1995, p. 27), "as situações que os professores são obrigados a enfrentar apresentam características únicas, exigindo, portanto, respostas únicas”. As práticas de formação instituídas nos espaços educativos devem tomar como referência as dimensões individuais e coletivas da profissão docente, num movimento que compreenda o compartilhamento de experiências entre pares e a autonomia de cada professor acerca "da responsabilidade do seu próprio desenvolvimento profissional" (1995, p.27). Nóvoa aponta a necessidade de passar a formação de professores para "dentro" da profissão, tomando como base as situações que vivenciam em seus contextos escolares, oportunizando o diálogo entre pares em sua própria instituição, na busca de soluções que venham de encontro aos dilemas e experiências de cada equipe de ensino em sua realidade singular. 
Sendo assim, a formação in loco tem como objetivo contribuir para o aprimoramento da prática pedagógica do professor. Visa-se promover reflexões sobre a prática em sala de aula, socializando experiências didático-metodológicas, avaliando o processo de formação de modo compartilhado, sistematizando ideias, teorizando e produzindo saberes e fazeres pedagógicos específicos da Educação Infantil.

Remetendo este pensamento ao contexto da Educação Infantil, isto implica em oportunizar aos profissionais espaços de avaliação e discussão entre as demais atividades desenvolvidas nas instituições, para que a formação aconteça como um processo contínuo e integrado ao cotidiano, configurada não somente como necessidade, mas como direito e premissa para a oferta de uma Educação Infantil de qualidade.

A formação é necessária não apenas para aprimorar a ação do
profissional ou melhorar a prática pedagógica. A formação é direito de
todos os professores, é conquista e direito da população, por uma
escola pública de qualidade. Podem os processos de formação
desencadear mudanças? Sim, se as práticas concretas feitas nas
creches, pré-escolas e escolas e aquilo que sobre elas falam seus
profissionais forem o ponto de partida para as mudanças que se
pretende implementar (KRAMER, 2005, p. 224).

A oferta de formação in loco como prática a ser garantida pelas redes de ensino, conforme preceito no artigo 62 , inciso $1^{\circ}$ da Lei $n^{\circ} 9.394 / 96$, e suas alterações $n^{\circ}$ 12.796/2013 “a União, o Distrito Federal, os Estados e os Municípios, em regime de colaboração, deverão promover a formação inicial, a continuada e a capacitação dos profissionais de magistério" (BRASIL, 1996), ainda encontra desafios.

Para garantir uma educação infantil de qualidade com uma ação pedagógica adequada é crucial que o educador tenha uma boa formação inicial para que ele possa organizar seu trabalho a partir dos dez preceitos considerados importantes para essa prática de acordo com KULISZ (2006, p. 29-30), os quais consideramos fundamentais para a educação de crianças pequenas, quais sejam: organização do espaço e materiais; equilíbrio entre atividades livres e dirigidas, garantidas no planejamento; atenção privilegiada aos aspectos emocionais; utilização de uma linguagem enriquecida e adequada; diferenciação de atividades para abordar todas as dimensões do desenvolvimento e todas as capacidades; rotina estável; materiais diversificados e polivalentes; olhar atento e, se possível, individualizado a cada criança; sistema de avaliação e anotações, que permitam o 
acompanhamento global do grupo e de cada uma das crianças, e o trabalho com os pais e as mães e com o meio ambiente.

Estes preceitos somados à importância do trabalho com diferentes projetos temáticos, ações pedagógicas que envolvam também momentos do banho, da alimentação e de outros cuidados básicos contribuem sobremaneira para uma Educação Infantil de qualidade sendo, portanto fundamentais no processo de formação e desenvolvimento integral da criança. Tais projetos empreendem ações educativas sobre diversos conceitos, habilidades e atitudes infantis, favorecendo a potencialização das diferentes habilidades da criança.

Cabe enfatizar que tais preceitos não são percebidos pela equipe da escola, lócus deste trabalho, como receitas prontas, representam sim, a possibilidade de ressignificação do espaço infantil e sua organização educacional, vislumbrando pontos fundamentais que contribuem com as ações e reflexões no interior do ambiente escolar, sendo instrumento da discussão, reflexão, reconstrução e transformação coletivas na EMEI Zacarias Pereira da Silva, de forma a pensar e repensar o trabalho nas escolas visando um atendimento de qualidade, com a garantia do direito das crianças a viverem a infância, e de auxiliá-las em seu desenvolvimento social, cognitivo e afetivo.

\section{Formação 'in loco'...}

Como ponto de partida para o desenvolvimento deste trabalho de formação in loco, consideramos primeiramente a diversidade na Educação Infantil em uma proposta de reflexão conjunta com os profissionais envolvidos de modo a nos permitir dialogar e conhecer os saberes docentes sobre esse público, suas concepções, o que sabem e o que pensam a respeito da diversidade de crianças com as quais interagem, e discutir sobre as ações que possam potencializar os saberes individuais dos alunos e ainda analisar e refletir sobre os pressupostos que os influência. Essa dinâmica de trabalho supõe a problematização, a busca coletiva de soluções dialogando com os estudiosos e educadores considerados aportes teóricos fundamentais para a interpretação e reconstrução da prática pedagógica.

Para que este momento de formação continuada in loco cumpra seu objetivo, devemos considerar um outro aspecto importante que o sustenta que diz respeito ao tipo de relação que é estabelecido entre as professoras formadoras e o grupo de 
profissionais. Assim, consideramos de suma importância criar condições emocionais favoráveis, com vínculos afetivos reais entre os profissionais e deles com as formadoras. Sabemos que a interação é fundamental em todo e qualquer processo de aprendizagem, com crianças e/ou com adultos. A construção de uma condição favorável à aprendizagem pressupõe confiança, paciência, respeito às diferenças, seja de posicionamento e/ou de saberes, pressupõe ainda espaço para a divergência e a confrontação, atitudes estas que devem ser previstas e trabalhadas como conteúdo que integram o processo de formação. Utilizamos como estratégias formativas:

I. Desdobramentos e alternâncias de formadores na EMEI Zacarias Pereira da Silva, contribuindo também como professoras formadoras a Diretora e a Pedagoga, enriquecendo o trabalho e representando sua individualidade de olhar;

II. Levantamento dos interesses formativos e tabulação dos dados par estruturação e organização de uma formação mais próxima da experiência e realidade do contexto;

III. Organização dos horários, programação, cronograma de execução e espaço de formação na EMEI Zacarias Pereira da Silva, local dos encontros de formação a fim de sistematizar a formação;

IV. Proposição de leituras e discussões de textos selecionados previamente para cada encontro de formação.

V. Momentos dedicados à prática, a partir da reflexão do material em estudo;

VI. Palestras, oficinas e debates sobre os temas de interesse e atendendo, na medida do possível, aos anseios dos docentes;

VII. Reflexão e análise de situações práticas a partir de vídeo/produção das crianças, relatos de experiências dos profissionais favorecendo a conscientização e a percepção de situações-problemas, auxiliando na perspectiva da solução;

VIII. Observação de atividades realizadas com as crianças, seguidas de reflexão.

IX. Construção de relatórios como instrumento que possibilita a reflexão organizada sobre a prática.

X. Registro fotográfico. 


\section{Algumas considerações}

Pensar a Educação Infantil, implica considerar os vários aspectos próprios da infância, sendo necessário, portanto pensar também nos profissionais que atuam diretamente com as crianças, que tão pequenas necessitam de um olhar atento e sensível as suas múltiplas linguagens, suas múltiplas maneiras de ver e estar no mundo. Essa é uma etapa que carece de profissionais capacitados que percebam o público da Educação Infantil na sua dimensão histórico social, como um sujeito que produz cultura, que cria e constrói hipóteses sobre a vida, sobre as coisas, sobre o mundo, etc.

O desafio apresentado neste trabalho é o de fato buscar a coerência entre um modelo de formação continuada que seja espaço promotor de reflexão, de análises e de desenvolvimento profissional e o modelo de ensino e aprendizagem que é conteúdo de sua formação. Os professores e educadores infantis têm o direito de experienciar, em seu próprio processo de aprendizagem, práticas orientadas para o desenvolvimento do pensamento crítico, da aprendizagem ativa, da criatividade, da autonomia, de valores democráticos, do exercício da cidadania...

Esse relato de experiência não tem um fim em si mesmo, pretende ser instrumento de questionamento e ressignificação do fazer e saber docente, de modo a contribuir não apenas para a Educação Infantil de qualidade, mas também para a formação continuada de qualidade para o docente, compreendendo a complexidade e multiplicidade do saber e do fazer pedagógico.

\section{Referências Bibliográficas:}

BRANDÃO, A. C. P.; ROSA, E. C. de S. Ler e escrever na Educação Infantil: discutindo práticas pedagógicas. Belo Horizonte: Autêntica Editora, 2010.

BRASIL. Lei n. 9394/96. Lei de Diretrizes e Bases da Educação Nacional. Estabelece as diretrizes e bases da educação nacional. Diário Oficial União, Brasília, DF, v. 134, n. 248, 23 dez. 1996. Seção 1, p. 27834-27841.

. Lei 12.796/13. Lei que altera a lei 9394/96. D.O.U. DE 05/04/2013, P. 1. 
BUJES, M. I. E. Escola infantil: pra que te quero? In: CRAIDY, C. M.; KAERCHER, G. E. P. S. (Org.). Educação Infantil: pra que te quero? Porto Alegre: Artmed, 2001, p. 13-22.

CEDAC. Comunidade Educativa. O que revela o espaço escolar? Um livro para diretores de escola. 1. ed. São Paulo: Editora Moderna, 2013, 157 p.

FRIDMANN, Adriana. O brincar na educação infantil; observação, adequação e inclusão. 1 ed. São Paulo: (Cotidiano Escolar: ação docente) Moderna, 2012.

FUNDAÇÃO TELEFÔNICA. A importância da cultura na educação infantil. 2014. Disponível em:<http://fundacaotelefonica.org.br/noticias/a-importancia-da-cultura-naeducacao-infantil/>. Acesso em: 10 mar. 2016.

KRAMER, S. Profissionais de Educação Infantil: Gestão e Formação. São Paulo: Ática, 2005.

KULIZS, Beatriz. Professoras em cena: O que faz a diferença? Mediação, 2006

LINO, Dalila Brito. A Rotina diária nas Experiências-chave do Modelo High/Scope. In: ZABALZA, Miguel. Qualidade em Educação Infantil. Porto alegre: Artmed, 1998 [p. 185-20].

MELLO, S. Al. A Apropriação da Escrita como Instrumento Cultural Complexo. In: MENDONÇA, S. G. de L.; MILLER, S. (Orgs). Vigotski e a Escola Atual: fundamentos teóricos e implicações pedagógicas. 2. ed. Araraquara: J.M. Editora e Cultura Acadêmica Editora, 2010.

NÓVOA, A. Os professores e sua formação. Lisboa: Dom Quixote, 1995.

SANTOMAURO, B. Usar a TV na Educação Infantil sem propósito. Revista Nova Escola. Edição 224, Agosto, 2009. Disponível em: <http://revistaescola.abril.com.br/formacao/assim-nao-usar-tv-educacao-infantilproposito-487229.shtml>. Acesso em: 11 mar. 2016.

UBERLÂNDIA. Lei 11.967, de 29 de Setembro de 2014 que dispõe sobre o Plano de Carreiras dos Servidores do Quadro da Educação da Rede Municipal de Ensino de Uberlândia. Diário Oficial do Município, Uberlândia, MG, Ano XXVI, n. 4493, 29 set. 2014. p. 155-207.

UBERLÂNDIA. Lei 12.316, de 24 de Novembro de 2015 que dispõe sobre o Plano de Carreiras dos Servidores do Quadro da Educação da Rede Municipal de Ensino de Uberlândia. Diário Oficial do Município, Uberlândia, MG, Ano XXVII, n. 4776, 24 nov. 2015. p. 9.

UBERLÂNDIA. Lei n. 11.444/13. Lei Rede Pelo Direito de Ensinar e Aprender. Institui a Rede Pública Municipal pelo Direito de Ensinar e Aprender no Município de Uberlândia. Diário Oficial do Município, Uberlândia, MG, Ano XXV, n. 4203, 26 jul. 2013. p. 1-3. 